\title{
RESEARCH ON INDUSTRIAL ASSEMBLY LINE BALANCING OPTIMIZATION BASED ON GENETIC ALGORITHM AND WITNESS SIMULATION
}

\author{
Wang, Y.,\# \& Yang, O.** \\ *School of Electronics and Communication Engineering, Shenzhen Polytechnic, Shenzhen 518055, \\ China \\ ${ }^{* *}$ School of Computer Engineering, Shenzhen Polytechnic, Shenzhen 518055, China \\ E-Mail: wyang@szpt.edu.cn ( ${ }^{\#}$ Corresponding author)
}

\begin{abstract}
With the rapid development of the industry sector, the assembly line has also experienced development, whose rationality determines the production efficiency of industrial production. In this paper, in order to address the balancing issue of assembly lines for industrial production, a combinatorial optimization method is proposed for the optimization and implementation of the assembly line based on the improved genetic algorithm (GA) and system simulation. By being applied to the assembly line of a company's chiller, our method is proved practical and effective.

(Received, processed and accepted by the Chinese Representative Office.)
\end{abstract}

Key Words: GA, Witness Simulation, Assembly Line, Balance Problem, Combinatorial Optimization

\section{INTRODUCTION}

The development of the industry sector determines the speed and level of the development of the national economy. The aim of industry is to process and assemble raw materials and other materials into different kinds of goods to meet the needs of people's daily life, including transportation equipment, articles for daily use, electronic equipment, and metallurgy. In order to satisfy the requirements of its developing national economy, it has long been a priority of China to introduce advanced technology which can improve industrial productivity and efficiency. The assembly line is the key to greatly improving production efficiency [1-2]. With the rapid development of technology, different kinds of assembly lines have emerged, such as U-type assembly lines and hybrid assembly lines [3-4]. However, the country is faced with the assembly line balancing issue, i.e. how to simultaneously distribute processing elements to different workbenches in a rational way and satisfy regulated production rhythms so that the waiting time of labourers and equipment is reduced [5]. The problem of assembly line balance has a great impact on improving the quality of processing, workers' enthusiasm, and production efficiency.

Since the issue of assembly line balance has been put forward, many scholars have been working on the problem. Erel and Gokcen [6], Gökçen et al. [7] proposed the shortest route algorithm tailor-made for the hybrid production assembly line, which can only be applied to the large-scale assembly line balancing problem in a limited way. Pierreval et al. [8], Manavizadeh et al. [9], Koç [10] used the GA to explore this issue. Meanwhile, the GA was used to improve the balancing issue $[11,12]$. Other commonly-used algorithms include the simulated annealing algorithm [13], tabu search algorithm [14], and branch and bound algorithm $[15,16]$. The application system simulation method is also one of the effective methods. Related examples are the use of Petri net technology for modelling and simulation $[17,18]$, the application of the discrete event analysis method to establish models, and the realization of such models with simulation software [19]. 
In this paper, the GA is used to analyse and improve the assembly line balancing issue so as to optimize the assembly line. We take into account the advantages and disadvantages of the GA and system simulation, combine the GA with the Witness system via simulation, and propose a combinatory optimization method for the optimization and implementation of the assembly line. By being applied to the assembly line of a company's chiller, our method is proved practical, effective, and of theoretical and guiding significance for industrial assembly production.

\section{ANALYSIS AND IMPROVEMENT OF GA}

\subsection{Assembly line balancing problem}

Our research purpose here is to improve the production efficiency of assembly lines. Specifically speaking, we find the most reasonable solution for the task distribution for the given maximum number of workbenches so as to minimize the production rhythm of the assembly line. At the same time, on the premise of the minimal production rhythm, we ensure the minimization of the balancing index of load balance. On the premise of the minimal balancing index of load balance, we ensure the maximization of correlation coefficients between task elements. Before studying the balancing issue, we have the following assumptions: One task element should neither be assigned to two or more workbenches at the same time nor be re-divided into sub-elements; the operating time for each element is independent and fixed; the workbenches in the assembly line are serial; each worker in the assembly line can complete any of the task elements.

Through the above assumptions, we establish the corresponding mathematical models, whose objective function is:

$$
\operatorname{Min} f=\omega_{1} \times C T+\omega_{2} \times S I-\omega_{3} \times R Q
$$

where $C T$ is the production rhythm, $S I$ is the balancing index, $R Q$ is the correlation coefficient of the task element, $\omega_{1}, \omega_{2}$ and $\omega_{3}$ are positive, and $\omega_{1} \prec \omega_{2}, \omega_{2} \prec \omega_{3}$.

The balancing index is expressed as:

$$
S I=\sqrt{\sum_{i=1}^{m}\left(C T-S T_{i}\right)^{2} / m}
$$

where $S T_{i}$ is the work time assigned to every workbench, and $m$ is the number of workbenches.

$$
R Q=\sum_{i=1}^{m} R_{i}
$$

in which $R_{i}$ is the numerical sum of precedence matrix values between task elements in all workbenches. The larger $R_{i}$ is, the more reasonable the result is.

Constraint conditions:

a: Determine the number of workbenches $m$;

b: $S_{i} \cap S_{j}=\varnothing, i \neq j, i=1,2, \ldots, m, j=1,2, \ldots, m$

c: $\bigcup_{k=1}^{m} S_{k}=E, k=1,2, \ldots, m$; where $E$ is the task element set and $S_{k}$ is the sum of task elements contained in all workbenches.

d: $T\left(S_{k}\right) \leq C T, k=1,2, \ldots, m$, i.e. the work time in each workbench should not exceed the work rhythm.

e: $M=\left(M_{i j}\right)_{n \times n}$ is a $n \times n$ precedence matrix $(0,1)$. If $M_{i j}=1, i \in S_{x}, i=j \in S_{y}$, then $x \leq y$. 


\subsection{The improved GA}

a: Encoding design:

We use sequence coding to line task elements and assign them to workbenches according to the sequential order. The codes of all task elements are the corresponding gene bits.

b: Decoding design:

We calculate from the minimum calculation beat $C_{\text {theory }}$ and initialize $C T_{1}=C_{\text {theory }}$. If the minimum number of workbenches obtained at this time is equal to the given number $\mathrm{m}$, then $C_{\text {theory }}$ is the minimum beat:

$$
C_{\text {theory }}=\sum_{j=1}^{n} T_{j} / m
$$

With $C T_{1}$ as the rhythm, we assign task elements to all workbenches, $S T_{m}>C T_{1}$. If $S T_{m} \leq C T_{1}$, the solution obtained is the optimal one, or otherwise we repeat the steps. Then, we let $\Delta_{k}=S_{k}+{ }_{1}$, where $\Delta_{k}$ is the incremental adjustment of $S_{k}, k=1,2, \ldots, m-1$. Meanwhile, we let $C T 1=\min _{1 \leq k \leq m-1}\left\{S T_{k}+\Delta_{k}\right\}, C T 2=\max _{1 \leq k \leq m}\left\{S T_{k}\right\}$. If $C T_{1} \geq C T_{2}$, then $C T_{2}$ is the minimum beat at this sequential order. In this case, the circular calculation can be stopped, or else it continues.

c: The fitness function equation:

$$
F(P)=\sum_{i=1}^{m} S T_{i}^{2}
$$

where $P$ is a single chromosome, and the greater the fitness value is, the better the chromosome is [20].

$\mathrm{d}$ : Population initialization:

We first search in the finite matrix for elements whose column is zero as the free element set. Then, we choose arbitrary elements from this set one by one to assign them to the workbench while deleting the element's row and column in the precedence matrix until all the elements have been assigned.

e: Select the operator:

Select the individual in the population for the mapping $T_{s}: S^{N} \rightarrow S$ according to the following formula:

$$
P\left\{T_{s}^{\alpha}(\vec{X})=X_{i}\right\}=\frac{F^{\alpha}\left(X_{i}\right)}{\sum_{k=1}^{N} F^{\alpha}\left(X_{k}\right)}
$$

where $\alpha$ is the proportional selection operator which is equal to 1 in this paper.

The details of the algorithm are: We first sequence the fitness degree $F\left(P_{r}\right)$ of a chromosome in the initialized population in an ascending order, and then accumulate the value of $F\left(P_{r}\right)$ according to the following formula, in which $A\left(P_{r}\right)=\Sigma P\left(P_{r}\right)$.

$$
P\left(P_{r}\right)=\frac{F\left(P_{r}\right)}{\sum F\left(P_{r}\right)}
$$

Table I is the probability selection table.

Table I: Probability selection table.

\begin{tabular}{|c|c|c|c|c|}
\hline Chromosome & $P_{1}$ & $P_{2}$ & $\ldots$ & $P_{n}$ \\
\hline Probability $F\left(P_{r}\right)$ & $P\left(P_{1}\right)$ & $P\left(P_{2}\right)$ & $\ldots$ & $P\left(P_{n}\right)$ \\
\hline$A\left(P_{r}\right)$ & $P\left(P_{1}\right)$ & $P\left(P_{1}\right)+P\left(P_{2}\right)$ & $\ldots$ & 1 \\
\hline
\end{tabular}

A random number rand is generated from [0, 1]. If $A\left(P_{r}\right)<\operatorname{rand}<A\left(P_{r+1}\right)$, the chromosome $P_{r+1}$ is regarded as the new population. As a result, it is deleted from the initial 
population. We repeat this procedure until obtaining the number of chromosomes $\mathrm{CN}$ as required.

f: Hybrid operator:

We first calculate the number of pairs $\left|\frac{1}{2} C N \times p_{c}\right|$, in which $p_{c}$ is the hybrid probability; we generate two integers differing in value rand 1 and the larger $r a n d 2$, and then genes falling within the interval of [rand1, rand2] are hybrid. Their corresponding hybrid zone is mapped into the $P_{1}$ and $P_{2}$ chromosomes before hybridization. Hybrid genes in $P_{1}$ are re-ordered according to the orders in $P_{2}$, and the same process is applied to P2 hybrid genes. The subchromosomes obtained this way are recorded as $P_{1 \_}$new and $P_{2 \_}$new. We then calculate the fitness of the new chromosomes. New chromosomes with larger fitness will be the candidates waiting for SI value optimization according to common methods, or else the original chromosome will be retained with its population number $\mathrm{CN}$ unchanged.

\section{$\mathrm{g}$ : Mutation operator}

In this paper, according to the characteristics of the assembly line, we introduce the initial mutation point $P_{s m}$ and the terminal mutation point $P_{e m}$. The larger the number of task elements is, the greater $P_{s m}$ is. The reverse is also true. Table II shows the corresponding mutation sector.

Table II: Corresponding mutation sector.

\begin{tabular}{|l|c|c|c|c|c|c|}
\hline \multicolumn{1}{|c|}{ Node number } & $<50$ & $P_{s m}$ & $14 \%$ & $P_{e m}$ & $86 \%$ & \\
\hline Mutation sector & $14 \%-38 \%$ & $38 \%-62 \%$ & $62 \%-86 \%$ & - & - & - \\
\hline $\begin{array}{l}\text { Corresponding } \\
\text { random number }\end{array}$ & 1 & 2 & 3 & - & - & - \\
\hline Node number & {$[50,100]$} & $P_{s m}$ & $10 \%$ & $P_{e m}$ & $90 \%$ & \\
\hline Mutation sector & $10 \%-30 \%$ & $30 \%-50 \%$ & $50 \%-70 \%$ & $70 \%-90 \%$ & - & - \\
\hline $\begin{array}{l}\text { Corresponding } \\
\text { random number }\end{array}$ & 1 & 2 & 3 & 4 & - & - \\
\hline Node number & {$[100,200]$} & $P_{s m}$ & $7 \%$ & $P_{e m}$ & $92 \%$ & - \\
\hline Mutation sector & $7 \%-24 \%$ & $24 \%-41 \%$ & $41 \%-58 \%$ & $58 \%-75 \%$ & $75 \%-92 \%$ & - \\
\hline $\begin{array}{l}\text { Corresponding } \\
\text { random number }\end{array}$ & 1 & 2 & 3 & 4 & 5 & - \\
\hline Node number & $\geq 200$ & $P_{s m}$ & $5 \%$ & $P_{e m}$ & $96 \%$ & - \\
\hline Mutation sector & $5 \%-20 \%$ & $20 \%-35 \%$ & $35 \%-50 \%$ & $50 \%-65 \%$ & $65 \%-80 \%$ & $80 \%-95 \%$ \\
\hline $\begin{array}{l}\text { Corresponding } \\
\text { random number }\end{array}$ & 1 & 2 & 3 & 4 & 5 & 6 \\
\hline
\end{tabular}

\section{COMBINATORY OPTIMIZATION OF ASSEMBLY LINE BALANCING ISSUE}

Despite its quickness and efficiency in addressing optimization problems, the GA is less intuitive and convenient in handling random distribution functions than a computer system is. The effective combination of simulation technology and the GA thus generates an efficient tool to address complicated optimization problems while describing problems and schemes in an intuitive manner. The combinatorial optimization method proposed in this paper is shown in Fig. 1.

The first step is an optimization of a single task element in order to improve its operating efficiency. We take measures mainly to improve the rationality of man-machine combination, action analysis, and action simulation. Through the analysis of the operation target and process of the man-machine combination, we undertake the reasonable assignment to enhance productivity by reducing labour intensity, waiting time, and enforced idleness. 


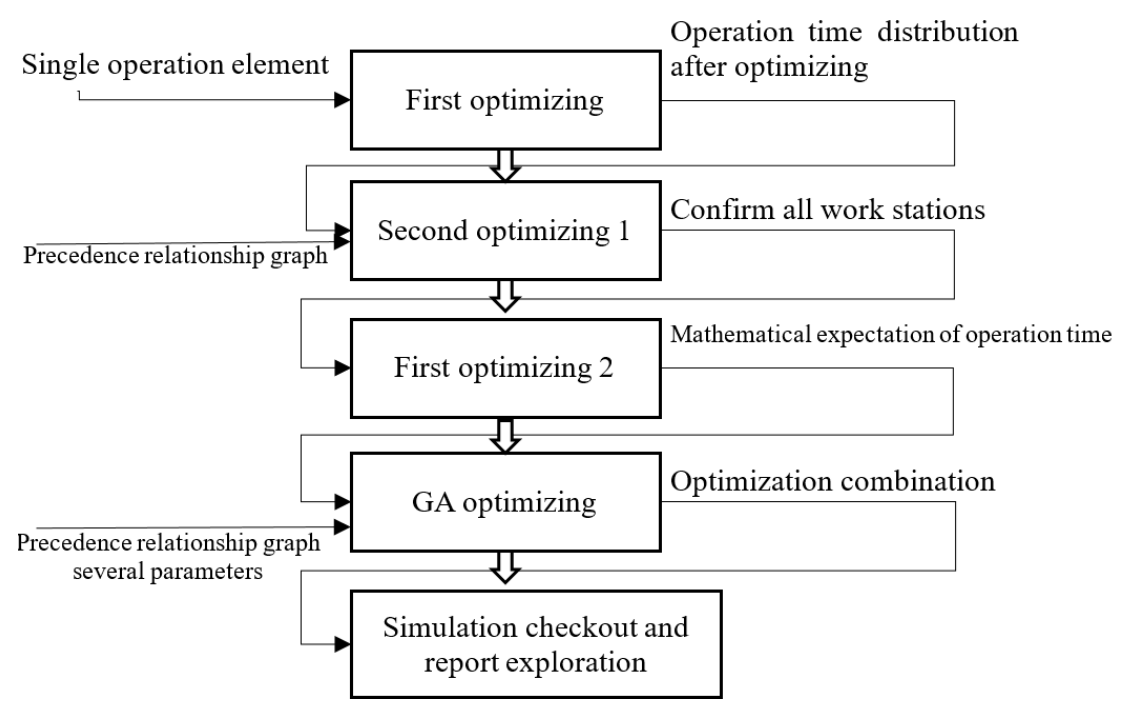

Figure 1: Flow chart of hybrid optimization algorithm.

Action analysis is intended to reduce or eliminate redundant actions of workers and machines and to optimize non-standard actions, thus saving time and using a smaller labour force. With action analysis, the entire production line can be rendered more smooth, convenient, and quick-to-handle on the premise of work safety. Action simulation is the computer simulation of human actions, in which related parameters are adjusted according to physical fitness so as to mitigate fatigue, improve the fluency of actions, and work towards the maximum rationality of the entire production line.

The second step is a second optimization by means of system simulation, which mainly involves the determination of operation times of each task element according to the production task priority diagram. The Witness software is used for system simulation and assembly line modelling with parameters of machine type, processing time probability, the number of workbenches, operating elements, and so on. We run the analysis to obtain the minimum number of free-type task elements before re-inputting it for a 1,000-time repeated simulation operation. In this way, we determine the average operating time.

The third step is to improve the GA optimization. By using the production task priority diagram, we obtain the optimal combinatory mode of operating elements, which means to minimize the value of Eq. (1). The details of analysis and computation that have been mentioned above are programmed for realization through MATLAB software.

Finally, the model is reconstructed according to the above steps and undertakes simulation. In this way, the simulation analysis result is obtained.

\section{EXAMPLE APPLICATION}

In order to verify the combination optimization method proposed in this paper, a company's compressor chiller assembly line is used as an example here for the analysis of the object. Due to the limitations of the company site, there are at most 14 workbenches that can be placed on the assembly line. In light of the high cost of mechanical operation for some of the assembly line tasks, we should take into consideration utilization rate and cost saving. The chiller contains components such as a cylinder, a water tank, an air compressor, a pipe assembly, a motor, an oil separator, and a circuit assembly. We arrange the assembly processes included in the assembly line so that the priority relationship between task elements in the improved assembly line is obtained, and plot it in Fig. 2. The names that correspond to each job element are listed in Table III. 


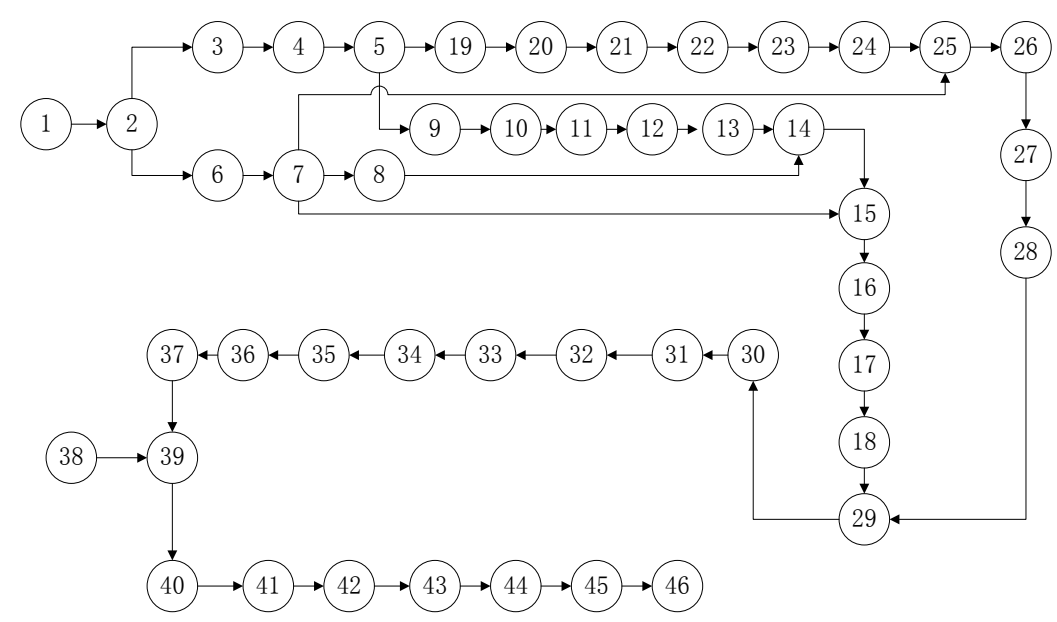

Figure 2: Precedence relation graph of cooling-water machine.

Table III: Designation of every operation element.

\begin{tabular}{|c|c|c|c|c|c|}
\hline No. & Operation & No. & Operation & No. & Operation \\
\hline 1 & Cutting & 17 & Attachment assembled & 32 & $\begin{array}{c}\text { Compressor unit assem- } \\
\text { bled }\end{array}$ \\
\hline 2 & $\begin{array}{c}\text { Sandblasting and shot } \\
\text { blasting }\end{array}$ & 18 & $\begin{array}{c}\text { Appearance clean and } \\
\text { check }\end{array}$ & 33 & Oil separator assembled \\
\hline 3 & Rolling & 19 & $\begin{array}{l}\text { Joint pipe flange assem- } \\
\text { bled }\end{array}$ & 34 & Pipeline installed \\
\hline 4 & Weldment & 20 & Sealing run & 35 & $\begin{array}{l}\text { Circuit control cabinet } \\
\text { installed }\end{array}$ \\
\hline 5 & Crack detection & 21 & $\begin{array}{l}\text { Admission port baffle } \\
\text { assembled }\end{array}$ & 36 & Electrical test \\
\hline 6 & $\begin{array}{c}\text { Finish machining of } \\
\text { orifice }\end{array}$ & 22 & Fluid baffle assembled & 37 & Unit air-tight test \\
\hline 7 & $\begin{array}{l}\text { Rough machining of } \\
\text { fixed orifice }\end{array}$ & 23 & $\begin{array}{l}\text { Supporting plate assem- } \\
\text { bled }\end{array}$ & 38 & $\begin{array}{l}\text { Water box component } \\
\text { assembly-welding }\end{array}$ \\
\hline 8 & Subcooler assembled & 24 & $\begin{array}{c}\text { Baffle backing ring as- } \\
\text { sembled }\end{array}$ & 39 & Water box assembled \\
\hline 9 & Joint pipe assembled & 25 & $\begin{array}{l}\text { Left and right tube plate } \\
\text { assembled }\end{array}$ & 40 & $\begin{array}{c}\text { Tube pass water pres- } \\
\text { sure test }\end{array}$ \\
\hline 10 & Weldment & 26 & $\begin{array}{l}\text { Retainer plate supporting } \\
\text { assembled }\end{array}$ & 41 & Holding \\
\hline 11 & Internals assembled 1 & 27 & Attachment assembled & 42 & Vacuum-pumping \\
\hline 12 & Internals assembled 2 & 28 & $\begin{array}{c}\text { Liquid-phase pipe assem- } \\
\text { bled }\end{array}$ & 43 & Oiling \\
\hline 13 & $\begin{array}{c}\text { Airtest clean and } \\
\text { check }\end{array}$ & 29 & $\begin{array}{l}\text { cold flashing tailor- } \\
\text { welding }\end{array}$ & 44 & Final assembly test \\
\hline 14 & Component assembled & 30 & Poling and pipe-expansion & 45 & Paint \\
\hline 15 & $\begin{array}{c}\text { Right tube plate as- } \\
\text { sembled }\end{array}$ & 31 & $\begin{array}{c}\text { Shell pass hydraulic air- } \\
\text { tight test }\end{array}$ & 46 & Package and despatch \\
\hline 16 & Weldment & & & & \\
\hline
\end{tabular}

The company produces a total of 12 types of chillers, of which there are three representative models whose processing time follows the distribution of $N\left(m_{1}, \sigma_{1}^{2}\right), N\left(m_{2}, \sigma_{2}^{2}\right)$, $N\left(m_{3}, \sigma_{3}^{2}\right)$. They are independent of each other at the production ratio of $5: 3: 3$. The first 31 task elements have the same operating time. Therefore, the weighed operating times of these three products still obey the normal distribution: 


$$
\begin{gathered}
E_{\text {all }}=E\left(\frac{5 E_{1}}{5+3+3}+\frac{3 E_{2}}{5+3+3}+\frac{3 E_{3}}{5+3+3}\right)=\frac{5}{11} E_{1}+\frac{3}{11} E_{2}+\frac{3}{11} E_{3}=\frac{5 \mu 1+3 \mu 2+3 \mu 3}{11} \\
D_{\text {all }}=D\left(\frac{5 D_{1}}{11}+\frac{3 D_{2}}{11}+\frac{3 D_{3}}{11}\right)=\frac{25}{121} D_{1}+\frac{9}{121} D_{2}+\frac{9}{121} D_{3}=\frac{25 \sigma_{1}^{2}+9 \sigma_{2}^{2}+9 \sigma_{3}^{2}}{121}
\end{gathered}
$$

According to the combination optimization method proposed in this paper, we first undertake one optimization by equating the operation time at each process with time spent by skilful workers to operate on the running machine. Meanwhile, we extract other related parameters. For example, the task time of the sub-cooler assembly in the $8^{\text {th }}$ process follows the distribution $\mathrm{N}(255,6)$ at the unit of minute. The task element type is single, the input/output ratio is $1: 1$, and the number of workbenches is 5 .

We establish Witness software models according to the assembly line of the chiller, and the firstly optimized parameters are inputted into the model. We let the simulation last for 2 years, and the effective work time is set as $7 \mathrm{~h}$ per day and $240 \mathrm{~d}$ per year. Therefore, the overall simulation time is $2 \times 240 \times 7 \times 60=364800 \mathrm{~min}$. We collate the simulation result data, finding that the processes with smaller than $90 \%$ extraction and utilization rate and more than one workbench are 28, 29,31,33,34, 35, and 37. Then, we optimize the number of workbenches, and the corresponding results are shown in Table IV.

Table IV: Quantity of workbenches after optimizing.

\begin{tabular}{|c|c|c|c|c|c|c|c|}
\hline No. & 28 & 29 & 31 & 33 & 34 & 35 & 37 \\
\hline Quantity & 6 & 2 & 6 & 3 & 3 & 3 & 4 \\
\hline
\end{tabular}

The optimized parameters are re-entered into the model for an operation of 1000 times. Then, we collate the operation time data of each task element and calculate their average value. The time is converted into the algorithm time. Afterwards, these data are inputted into the calculation program of the modified GA to obtain the optimal task element distribution method, as shown in Table $\mathrm{V}$.

Table V: Optimal distribution scheme.

\begin{tabular}{|c|c|c|c|}
\hline No. of workbench & Operation element & No. of workbench & Operation element \\
\hline 1 & 1 & 8 & $15,16,17,18,26,27$ \\
\hline 2 & $2,3,28$ & 9 & $29,35,37$ \\
\hline 3 & 7 & 10 & $30,32,34$ \\
\hline 4 & $4,9,10,19,20,21$ & 11 & $31,33,36$ \\
\hline 5 & 6 & 12 & $38,39,44$ \\
\hline 6 & $11,12,13,22$ & 13 & $40,42,43,45$ \\
\hline 7 & $8,14,23,24,25$ & 14 & 41,46 \\
\hline
\end{tabular}

Finally, we re-model the optimized parameters for the simulative analysis, and the corresponding result is shown in Fig. 2.

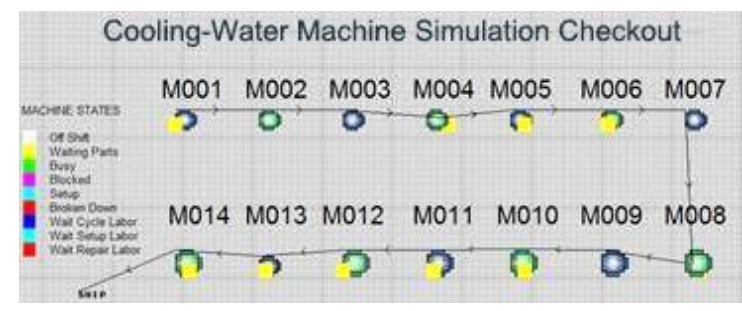

Figure 2: Simulation checkout graph of cooling-water machine.

The utilization ratio of each workbench is shown in Fig. 3. 


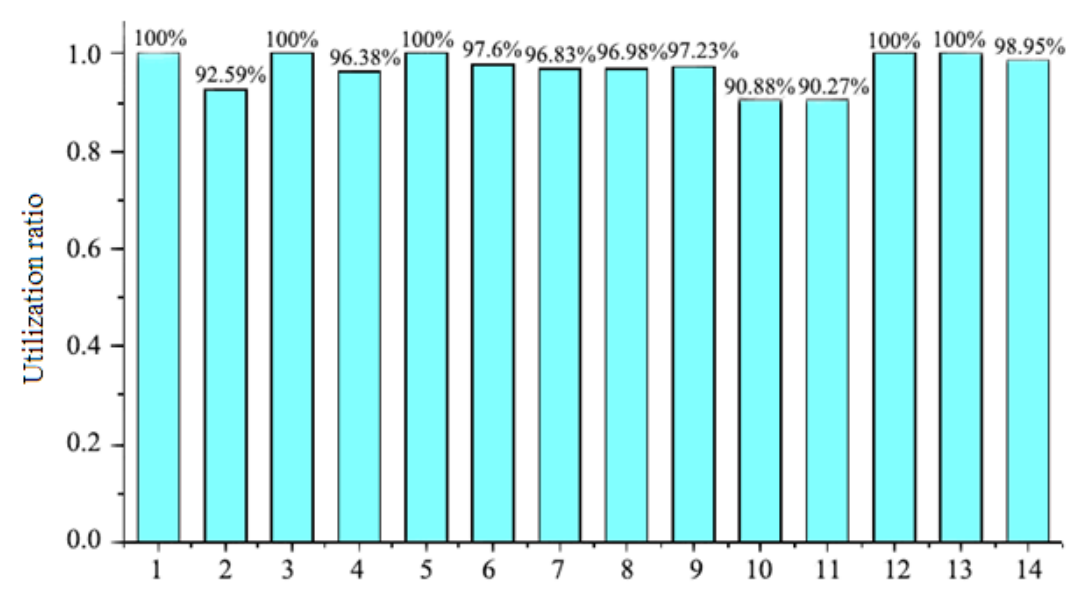

Figure 3: Utilization ratio of workbench.

It can be seen from Fig. 3 that the utilization rate of all workbenches is high: Workbenches No. 1, No. 3, No. 5, No. 12, and No. 13 are utilized $100 \%$, while the rest have an utilization rate as high as $90 \%$, meaning that all the optimized workbenches are utilized reasonably and fully. The adjusted $C T$ is 197.65 minutes, the balancing rate is $97.02 \%$, the balance index $S I$ is 9.41 , and the correlation coefficient $R Q$ of task elements is 25 . According to these data and Fig. 2, the optimized assembly line scheme has a good balance rate with close links between tasks and smooth task operation, which greatly improves production efficiency.

\section{CONCLUSION}

In this paper, in order to address the balancing issue of assembly lines for industrial production, a combinatorial optimization method is proposed for the optimization and implementation of an assembly line based on the improved GA and system simulation. Through case studies, our method is proved practical and effective.

(1) According to the characteristics of the assembly line, the GA is used to solve the balancing problem, and the optimization method is put forward with the integration of computer simulation technology. By effectively combining GA with Witness simulation, an assembly line can be optimized quickly and easily towards the direction of production efficiency improvement;

(2) The combinatorial optimization method proposed in this paper is used to simulate and optimize a company's chiller assembly line, and the results prove the effectiveness and practicability of our method.

\section{ACKNOWLEDGEMENTS}

This paper was supported by Guangdong IIOT(M-S) Engineering Technology Research Center and Shenzhen IIOT Engineering Laboratory, and Hubei Key Laboratory of Transportation Internet of Things (Wuhan University of Technology, No. 2016III028-004).

\section{REFERENCES}

[1] Becker, C.; Scholl, A. (2006). A survey on problems and methods in generalized assembly line balancing, European Journal of Operational Research, Vol. 168, No. 3, 694-715, doi:10.1016/j.ejor.2004.07.023

[2] Boysen, N.; Fliedner, M.; Scholl, A. (2007). A classification of assembly line balancing problems, European Journal of Operational Research, Vol. 183, No. 2, 674-693, doi:10.1016/ j.ejor.2006.10.010 
[3] Baykasoglu, A. (2006). Multi-rule multi-objective simulated annealing algorithm for straight and $\mathrm{U}$ type assembly line balancing problems, Journal of Intelligent Manufacturing, Vol. 17, No. 2, 217-232. doi:10.1007/s10845-005-6638-y

[4] Samouei, P.; Fattahi, P.; Ashayeri, J.; Ghazinoory, S. (2016). Bottleneck easing-based assignment of work and product mixture determination: fuzzy assembly line balancing approach, Applied Mathematical Modelling, Vol. 40, No. 7-8, 4323-4340, doi:10.1016/j.apm.2015.11.011

[5] Driscoll, J.; Thilakawardana. D. (2001). The definition of assembly line balancing difficulty and evaluation of balance solution quality, Robotics and Computer-Integrated Manufacturing, Vol. 17, No. 1-2, 81-86, doi:10.1016/s0736-5845(00)00040-5

[6] Erel, E.; Gokcen, H. (1999). Shortest-route formulation of mixed-model assembly line balancing problem, European Journal of Operational Research, Vol. 116, No. 1, 194-204, doi:10.1016/s0377-2217(98)00115-5

[7] Gökçen, H.; Ağpak, K.; Gencer, C.; Kizilkaya. E. (2005). A shortest route formulation of simple U-type assembly line balancing problem, Applied Mathematical Modelling, Vol. 29, No. 4, $373-$ 380, doi:10.1016/j.apm.2004.10.003

[8] Pierreval, H.; Caux, C.; Paris, J. L.; Viguier, F. (2003). Evolutionary approaches to the design and organization of manufacturing systems, Computers \& Industrial Engineering, Vol. 44, No. 3, 339-364, doi:10.1016/s0360-8352(02)00195-x

[9] Manavizadeh, N.; Rabbani, M.; Moshtaghi, D.; Jolai, F. (2012). Mixed-model assembly line balancing in the make-to-order and stochastic environment using multi-objective evolutionary algorithms, Expert Systems with Applications, Vol. 39, No. 15, 12026-12031, doi:10.1016/j.eswa.2012.03.044

[10] Koç, Ç. (2016). An evolutionary algorithm for supply chain network design with assembly line balancing, Neural Computing \& Applications, 13 pages, doi:10.1007/s00521-016-2238-3

[11] Tang, Q. H.; Liang, Y. L. (2012). The improved genetic algorithm for balancing mixed-model assembly line, Applied Mechanics \& Materials, Vol. 127, 603-608, doi:10.4028/ www.scientific.net/amm.127.603

[12] Xiao, N.; Rao, Y. L. (2016). Multi-product multi-period inventory routing optimization with time window constrains, International Journal of Simulation Modelling, Vol. 15, No. 2, 352-364, doi:10.2507/IJSIMM15(2)CO8

[13] Kanduc, T.; Rodic, B. (2016). Optimisation of machine layout using a force generated graph algorithm and simulated annealing, International Journal of Simulation Modelling, Vol. 15, No. 2, 275-287, doi:10.2507/IJSIMM15(2)7.335

[14] Özcan, U.; Toklu, B. (2009). A tabu search algorithm for two-sided assembly line balancing, The International Journal of Advanced Manufacturing Technology, Vol. 43, No. 7-8, 822-829, doi:10.1007/s00170-008-1753-5

[15] Wu, E.-F.; Jin, Y.; Bao, J.-S.; Hu, X.-F. (2008). A branch-and-bound algorithm for two-sided assembly line balancing, The International Journal of Advanced Manufacturing Technology, Vol. 39, No. 9, 1009-1015, doi:10.1007/s00170-007-1286-3

[16] Vilà, M.; Pereira, J. (2014). A branch-and-bound algorithm for assembly line worker assignment and balancing problems, Computers \& Operations Research, Vol. 44, 105-114, doi:10.1016/ j.cor.2013.10.016

[17] Wang, Y. R.; Chen, A. N. (2016). Production logistics simulation and optimization of industrial enterprise based on Flexsim, International Journal of Simulation Modelling, Vol. 15, No. 4, $732-$ 741, doi:10.2507/IJSIMM15(4)CO18

[18] Chandra, S.; Al Salamah, M.; Ali, V. (2014). Stochastic simulation of assembly line for optimal sequence using Petri nets (PN), IOSR Journal of Mechanical and Civil Engineering, Vol. 11, No. 2, 26-33, doi:10.9790/1684-11252633

[19] Chandra, V.; Huang, Z.; Kumar, R. (2003). Automated control synthesis for an assembly line using discrete event system control theory, IEEE Transactions on Systems, Man, \& Cybernetics Part C, Vol. 33, No. 2, 284-289, doi:10.1109/TSMCC.2003.813152

[20] Haq, A. N.; Rengarajan, K.; Jayaprakash, J. (2006). A hybrid genetic algorithm approach to mixed-model assembly line balancing, The International Journal of Advanced Manufacturing Technology, Vol. 28, No. 3, 337-341, doi:10.1007/s00170-004-2373-3 